\title{
The Effect of Misuse of Topical Corticosteroids on Skin
}

\author{
Deena K. Al-Samman*, Israa M. Al-Banna*, Wejdaan N. Al-Shakarchy*, Mohammed M. Attar-bashi** \\ Department of Pharmacology and Toxicology, College of Pharmacy, University of Mosul.** Ninevah Helth \\ Directorate, Ministry of Health, Iraq. Correspondence: Raheek_3@yahoo.com

$\frac{\text { Received }}{10.2 .2014} \quad \frac{\text { Accepted }}{13.3 .2014}$

\section{ABSTRACT}

Objectives: To assess the frequency of misuse of TC on skin, commonly used steroids and the most common dermatological problems resulting from it, as well as, to analyze the motives for such practices with the aim to raise awareness about this problem in Mosul city.

Methods: The study included 155 patients aged 0.8-49 years with dermatological disorders who attended Outpatient Department of Dermatology in Al-Salam Teaching Hospital in Mosul City. Inclusion criteria: those who had used TC without medical advice; continued use after short prescription regardless of the duration ;TC used incorrectly or used them for certain skin problems for which steroids are not indicated; Wrong indication (acne); undiagnosed dermatosis as well as a history of TC use continuously(for more than 1 month) or intermittently (for more than 3 months) due to any purpose, and presented with $\geq 1$ of the side-effects of these drugs as the chief complaint were criteria used to define unjustifiable/inappropriate use.

Patients with natural rosacea; those denying any history of using TC or who not consenting to answering the questionnaire; pregnant women; patients who were using prescribed TC regardless of the duration or side effects such as asthma, rheumatoid arthritis; patients with comorbidities that resembled/could cause changes similar to TC side-effects (polycystic ovaries / Cushing's syndrome/thyroid disorders)were excluded from the study. A questionnaire was designated and skin was examined to study patients. Results: Of the 155 subjects misused TC most were females $98(63.23 \%)$ and 57(36.77\%) were males; of low social class $45(29 \%)$. The majority $123(85.2 \%)$ thought that corticosteroid use was safe and 56(36.1\%) did not feel guilty for using such medications. Eighty fife $(55 \%)$ patients reported that physician and pharmacists advised them for the first time to use TC. Ninety eight $(63.3 \%)$ patients obtained the drug from the pharmacies, 30(19.3\%)from nurse staff and 27(17.4\%) from cosmetic shop/Beautician. lightening of the skin $(30.6 \%)$ was the main indication for use TC. Potent and very potent preparations were the main TC used by patients.Almost all had some features of TC side effects.

Conclusion: Inappropriate use of TC is a big problem in our country. Easy availability of very potent products without a prescription makes misuse very common which has a huge impact on dermatological practice. It is responsible for a significant proportion of visits to dermatology clinics. It is a multiphase problem that needs the cooperation of different sectors in the community to overcome it. Education of the general public through special media programs and the introduction of a continuing medical education programs for medical and paramedical personnel as well as controlling the easy intake from pharmacies are probably the most important steps that could be taken to reduce this problem.

Keywords: topical corticosteroids, misuse of topical corticosteroids, topical corticosteroids 


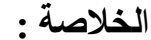

الأهداف: لتقييم وتيرة سوء استخدام الستيرويدات القترية الموضعية على الجلد، والأنواع الأكثر استخداما والمشاكل الجلدية

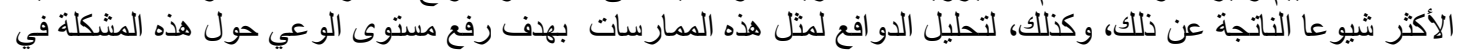

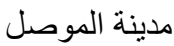
الأساليب: شملت الدراسة 155 مريضا تتر اوح أعمار هم بين 0،8 - 49 سنة بعانون من اضطر ابات جلدية والذين حضروا

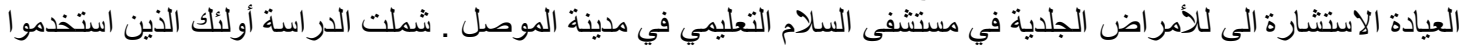

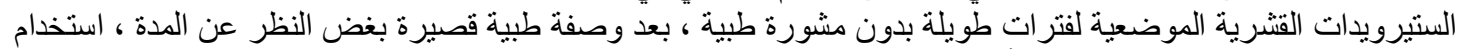

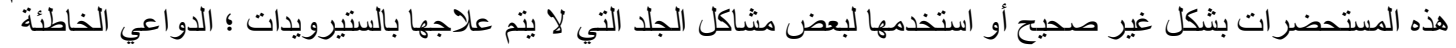

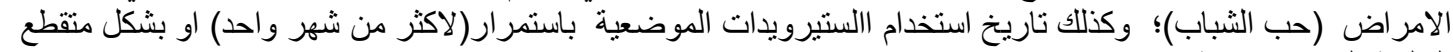

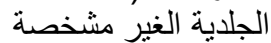

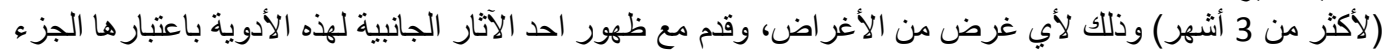

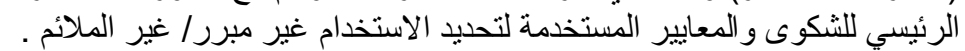

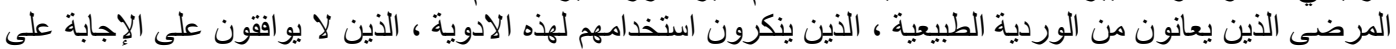

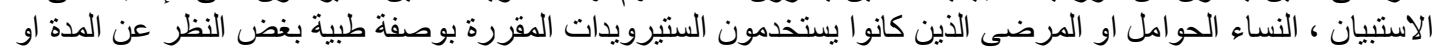

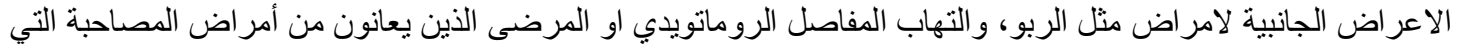

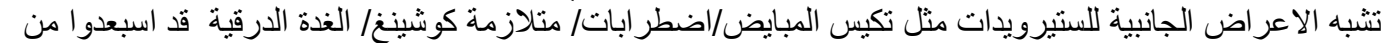

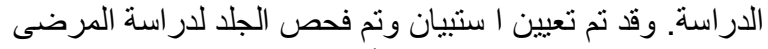

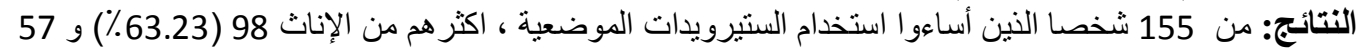

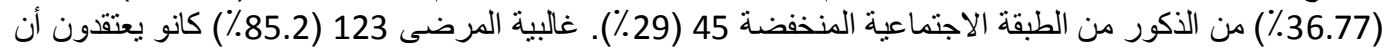

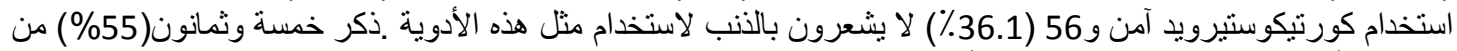

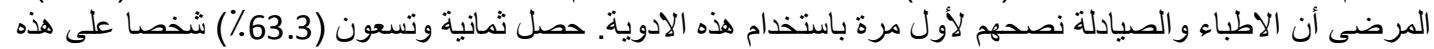

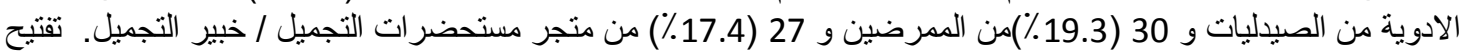

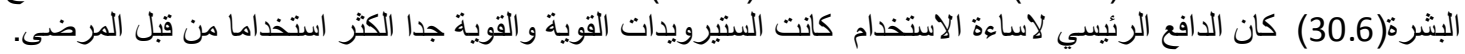

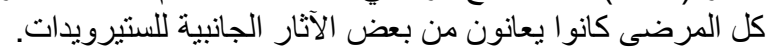

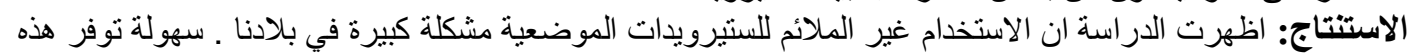

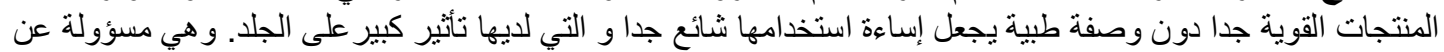

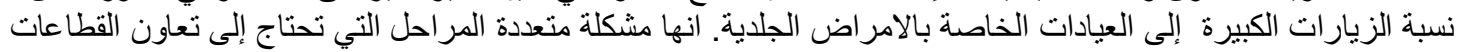

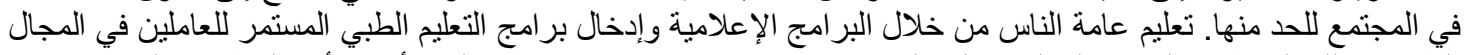

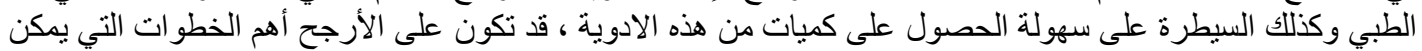
اتخاذها للحد من هذه المشكلة.
\end{abstract}

$\prod_{\text {corticosteroids (TC) since1950s }}^{\text {he development of topical }}$ represent a significant milestone in dermatologic therapy. They opened new doors for dermatologists previously faced with treating intractable dermatoses. TC are among the most commonly prescribed medication in an out-patient dermatology, probably no other group of drugs has had such a profound impact on the specialty as TC, which otherwise were the cause of significant morbidity among people ${ }^{(1-}$ 4).
However, over the years it has become increasingly apparent that TC are being abused by doctors and patients alike. Apart from the well-known indications such as psoriasis, dermatitis, vitiligo, lichen planus, etc., they are being used for conditions such as melasma, urticaria, and even undiagnosed skin rash by dermatologists and general physicians ${ }^{(5)}$. They provide rapid symptomatic relief in almost all inflammatory dermatoses. Even incorrect use, for instance in infectious dermatoses, produces an initial improvement in the symptoms. Apart 
from their anti-inflammatory effect, they also have potent antipruritic, atrophogenic, melanopenic, sexhormone-like and immunosuppressive effects on the skin. All these can lead to significant local adverse effects if TC are used indiscriminately ${ }^{(6)}$.

Commonly the person starts TC for primary dermatosis, for their antiinflammatory properties, however, with continuous misuse the steroid dermatitis will developed with its main clinical picture of erythema (local or diffuse), with its rebound phenomenon ${ }^{(7)}$. Paradoxically, the same mechanisms which mediate their underlie usefulness are also responsible for their adverse effects ${ }^{(8)}$. Besides the cutaneous and systemic adverse effects, the phenomenon of steroid addiction, tachyphylaxis, and contact dermatitis due to TC faced by dermatologists in many countries ${ }^{(9,10)}$.The problem is even more complex, wherein anyone can easily get a potent and very potent steroids without prescribed by a physician. Moreover, TCs have acquired a reputation as antiacne, antiblemish and fairness creams in general population,especially in countries with darker-pigmented races ${ }^{(11-14)}$.

Local side effects of TC, unlike systemic ones, are relatively frequent and becoming even more so with the introduction of the ultrahigh-potency topical corticosteroids.' Fortunately, systemic side effects are rare, but may occur, especially in infants' and elderly patients $^{(15)}$. The unwanted effects are directly related to their potency, and have become more prevalent with the introduction of high potency topical corticosteroids $^{(9)}$. They include effects on the epidermis and the dermis in addition to those resulting from systemic absorption $^{(16,17)}$.

TC misuse has been the subject of studies mainly from Africa and other
Asian countries ${ }^{(14,18)}$. However, even developed countries like the USA are facing this problem ${ }^{(19)}$. In fact, in recent years, the rapid rise in incidence of improper use of these drugs by dermatologists, general physicians, and patients threatens to bring disrepute to the entire group of these amazing drugs. Responsibility to disseminate proper knowledge regarding when, where, and how to use TC both to internists and patients rests primarily with the dermatologists. Benefits of rational and ethical use and the harm of overuse and misuse for nonmedical, specially for cosmetic purposes, should be clearly conveyed before penning a prescription involving $\mathrm{TC}^{(20)}$. The use of nonprescription potent $\mathrm{TC}$ has been noticed as a very common habit among the general population and was considered to be associated with increasing frequency of dermatological side-effects $^{(21)}$. Thus this dilemma stresses the need to alert the public to seek medical help instead of continuing this practice.

The aims of the present study are to assess the frequency of misuse of TC on skin, commonly used steroids and the most common dermatological problems resulting from it, as well as, to analyze the motives for such practices with the aim to raise awareness about this problem in Mosul city.

\section{Patients and Method}

This cross-sectional descriptive study was conducted, between March and August 2013, on patients who consulted the Dermatology Outpatient Department in Al-Salam Teaching Hospital in Mosul City, for dermatological problems, on 1 days / week.

Inclusion criteria for enrolled patients included patients who had used TC 
corticosteroid without medical advice; continued use after short prescription regardless of the duration; TC used incorrectly or used them for certain skin problems for which steroids are not indicated; wrong indication (acne); undiagnosed dermatosis as well as a history of TC use continuously(for more than 1 month) or intermittently (for more than 3 months) due to any purpose other than classical rosacea, and presented with $\geq 1$ of the side-effects of these drugs as the chief complaint were criteria used to define unjustifiable/inappropriate use. These side effects included the appearance of $\geq$ 1 of the following signs: Skin atrophy, facial redness, acne, rosecea, perioral dermatitis, plethoric face, telangectasia, hypertrichosis, striae, tinea incognito, hyper-hypopigmentation and milia.

Patients with natural rosacea; those denying any history of using TC or who not consenting to answering the questionnaire; pregnant women; patients who were using prescribed TC regardless of the duration or side effects such as asthma, nephrotic syndrome, rheumatoid arthritis; patients with comorbidities that resembled/could cause changes similar to TC side-effects (polycystic ovaries/Cushing's syndrome/thyroid disorders) were excluded from the study. A questionnaire was designated to include 2 sections: (a) Demographic profile including, sex, age, occupation and social class, (b) Information about TC therapy including; reasons for using TC ; frequency, duration and areas of the body involved as well as dermatological complications seen in patients who misused TC. Patients were also asked about the names and types of products used, the reason behind using such products; if the patients knew of the side effects of the drugs; guilty feeling for using nonprescription drugs; who had prescribed/recommended the remedy; source of drug; where they obtained those products. The name and type of corticosteroid were suggested by the patients according to formulation type and color in most of the cases. None of our patients gave the duration of using steroid exactly.

The diagnosis was established on clinical basis. The skin conditions which prompted the patients to visit the dermatology clinic were registered and the clinical details recorded. In addition, a full skin examination was performed to detect any condition related to misuse of TC. Patients of any age and of both sexes were recruited consecutively. Counseling and treatment of TC adverse effects was then started.

Numerical variables were reported as mean \pm standard deviation. Patients' characteristics will reported as percentages

\section{Results}

In this study there were 155 patients misused TC and met the criteria for inclusion; of these, $98(63.23 \%)$ were females and 57(36.77\%) were males, with ages ranging 0.8-49 years and mean of $28.6 \pm 10.8$ years. $31(20 \%)$ of these patients were children $<6$ years, $17(10.9 \%)$ students, 24(15.5) employed, $21(13.6 \%)$ teachers, $6(3.9 \%)$ paramedic, and56(36.1\%) were housewives.45(29\%) were from low social class, 79(51\%) from medium social class and $31(20 \%)$ from high social class (Table 1 ).

The main TC used were summarized in Table 2. Potent and very potent preparations were the main TC used by Patients.

Reasons for using corticosteroids products, frequency and duration of usage as well as dermatological complications 
seen in patients who misused $\mathrm{TC}$ are summarized in Table 3. The main reasons for using TC included lightening of the skin in $47(30.6 \%)$ patients. Some patients indicated $>1$ reason for using these medications. The main dermatological abnormalities seen due to application of TC was thinning of skin in 152 (98\%) patients. Acne and plethoric, puffy face with telangectasia (steroid face) were the most common adverse effects noted.
Stretch marks were seen in $34(21 \%)$ patients.

Ninety-seven $(62 \%)$ patients were not knew that used product containing steroids. $132(85.2 \%)$ patients realized that those dermatological problems were due to the use of TC. $99(63.9 \%)$ patients felt guilty because of using TC. The advisors for using TC and the sources of these products are listed in Table 4.

Table 1. Demographic features of enrolled patients $(n=155)$

\begin{tabular}{|c|c|c|}
\hline Characteristics & Number & $\begin{array}{c}\text { Percentage } \\
(\%)\end{array}$ \\
\hline Sex distribution & 57 & 36.77 \\
Male & 98 & 63.23 \\
Female & 21 & 13.5 \\
\hline Age (years) & 36 & 23.2 \\
$0.8-9$ & 59 & 38.1 \\
$10-19$ & 20 & 12.9 \\
$20-29$ & 19 & 12.3 \\
$30-39$ & & \\
$40-49$ & 31 & 20 \\
& 17 & 10.9 \\
\hline Occupation & 24 & 15.5 \\
Child $<6$ years & 21 & 13.6 \\
Student & 6 & 3.9 \\
Employed & 56 & 36.1 \\
Teacher & & \\
Paramedic & 45 & 29 \\
Housewife & 79 & 51 \\
Social class & 31 & 20 \\
Low & & \\
Medium & & \\
High & & \\
& & \\
\hline
\end{tabular}


Table 2. Type of TC, reason for using and dermatological abnormalities in patients who misused TC.

\begin{tabular}{|c|c|c|c|c|}
\hline $\begin{array}{c}\text { Trade name of } \\
\text { product } \\
\text { containing } \\
\text { steroids }\end{array}$ & Type of steroid content & $\begin{array}{c}\text { Potency } \\
\text { BNF } \\
\text { Classification }\end{array}$ & number & $(\%)$ \\
\hline $\begin{array}{c}\text { Betnosam } \\
\text { cream/ointment } \\
\text { Betnosam N } \\
\text { cream } \\
\text { Betnosam G } \\
\text { cream }\end{array}$ & $\begin{array}{c}\text { Betamethasone valerate } \\
0.1 \%\end{array}$ & Potent & $\begin{array}{c}33 \\
20 \\
5\end{array}$ & $\begin{array}{c}21.3 \\
13 \\
3.2\end{array}$ \\
\hline $\begin{array}{r}\text { Dermodin } \\
\text { cream } \\
\text { /oint } \\
\text { ment }\end{array}$ & $\begin{array}{c}\text { Clobetasol propionate } \\
0.05 \%\end{array}$ & Very potent & 32 & 20.6 \\
\hline $\begin{array}{c}\text { Nystacort } \\
\text { cream/ointment }\end{array}$ & Triamcinolone acetonide & Potent & 30 & 19.4 \\
\hline $\begin{array}{l}\text { Magic mix } \\
\text { (Corticosteroid } \\
\text { mixed with the } \\
\text { cosmetics) }\end{array}$ & $\begin{array}{l}\text { Betamethasone valerate } \\
0.1 \% \\
\text { and/or } \\
\text { Clobetasole propionate } \\
0.05 \% \\
\text { and/or } \\
\text { Dexamethasone powder } \\
\text { (crushed tablet) }\end{array}$ & $\begin{array}{c}\text { Potent } \\
\text { Very potent }\end{array}$ & 14 & 9 \\
\hline $\begin{array}{l}\text { Quadriderm } \\
\text { cream }\end{array}$ & $\begin{array}{c}\text { Betamethasone valerate } \\
0.5 \%\end{array}$ & Potent & 7 & 4.5 \\
\hline $\begin{array}{c}\text { Melacare } \\
\text { cream } \\
\text { Elica cream }\end{array}$ & Mometasone furoate $0.1 \%$ & Potent & $\begin{array}{l}6 \\
7\end{array}$ & $\begin{array}{l}3.9 \\
4.5\end{array}$ \\
\hline Others & & & 5 & 3.2 \\
\hline
\end{tabular}


Table 3. Reasons for using corticosteroids products, frequency and duration of usage as well as dermatological complications seen in patients who misused TC

\begin{tabular}{|c|c|c|}
\hline Parameters & Number & Percentage $(\%)$ \\
\hline \multicolumn{3}{|l|}{ Reasons for using preparations } \\
\hline Skin fairness \& Melasma & 47 & 30.6 \\
\hline Napkin rash & 25 & 16 \\
\hline Facial dryness & 19 & 12.4 \\
\hline Dermatitis & 17 & 11 \\
\hline Intertrigo & 15 & 9.7 \\
\hline Acne & 13 & 8.4 \\
\hline Fungal infections & 12 & 7.8 \\
\hline Scabies & 7 & 5.9 \\
\hline \multicolumn{3}{|l|}{ Frequency of application } \\
\hline Twice or fewer times per day & & 68 \\
\hline \multirow[t]{2}{*}{ Thrice or more times per day } & 106 & \\
\hline & 49 & 32 \\
\hline \multicolumn{3}{|l|}{ Duration of usage } \\
\hline Six months or less & 67 & 43 \\
\hline More than six months & 88 & 57 \\
\hline \multicolumn{3}{|l|}{ Complications } \\
\hline Skin atrophy & 152 & 98 \\
\hline Diffuse facial redness with hotness & 44 & 28 \\
\hline Facial acne & 39 & 25 \\
\hline Rosecea & 37 & 24 \\
\hline Plethoric face and telangectasia & 36 & 23 \\
\hline Striae & 34 & 21 \\
\hline Hypertrichosis & 32 & 20 \\
\hline Perioral dermatitis & 26 & 17 \\
\hline Tinea incognito & 22 & 14 \\
\hline Hyper-hypopigmentation & 19 & 12 \\
\hline Milia & 16 & 10 \\
\hline
\end{tabular}


Table 4. Misbelieves and attitudes about the use of topical corticosteroids.

\begin{tabular}{|c|c|c|}
\hline Questions & Number & Percentage (\%) \\
\hline $\begin{array}{l}\text { Is this product (containing steroid) safe? } \\
\qquad \begin{array}{c}\text { Yes } \\
\text { No }\end{array}\end{array}$ & $\begin{array}{l}97 \\
59\end{array}$ & $\begin{array}{l}62 \\
38\end{array}$ \\
\hline $\begin{array}{l}\text { Do you feel that this product harm your } \\
\text { skin? } \\
\text { Yes } \\
\text { No }\end{array}$ & $\begin{array}{c}132 \\
23\end{array}$ & $\begin{array}{l}85.2 \\
14.8\end{array}$ \\
\hline $\begin{array}{l}\text { Do you feel guilty? } \\
\text { Yes } \\
\text { No }\end{array}$ & $\begin{array}{l}99 \\
56\end{array}$ & $\begin{array}{l}63.9 \\
36.1\end{array}$ \\
\hline $\begin{array}{c}\text { The person who advices to use this product } \\
\text { Dermatologist } \\
\text { Nurse } \\
\text { Flea/street markets } \\
\text { Non dermatologist physician } \\
\text { Pharmacist } \\
\text { One of family members/ friend } \\
\text { Her/himself }\end{array}$ & $\begin{array}{c}49 \\
29 \\
27 \\
21 \\
15 \\
9 \\
5\end{array}$ & $\begin{array}{c}31.6 \\
18.7 \\
17.4 \\
13.6 \\
9.7 \\
5.8 \\
3.2\end{array}$ \\
\hline $\begin{array}{c}\text { Source of product? } \\
\text { Pharmacy } \\
\text { Nurse staff } \\
\text { Cosmetic shop/Beautician/flea } \\
\text { markets(magic mix) }\end{array}$ & $\begin{array}{l}98 \\
30 \\
27\end{array}$ & $\begin{array}{l}63.3 \\
19.3 \\
17.4\end{array}$ \\
\hline
\end{tabular}

\section{Discussion}

The findings of the our study confirm that the misuse of topical corticosteroids is quite common in our city. This is reflected by the large proportion of patients visited the dermatologists suffering from side- effects of these drugs. These findings concur with the view of prior studies reported from many countries worldwide, where TC misuse appears to be very widespread $^{(14,18-21)}$. 
The structural changes and the signs of chronologically aged skin and those of TC induced chronic atrophy of the skin are partially very similar. Thinning of skin and laxity as well as dryness occur in both conditions. So that, physicians can detect the misuse of TC agents in their patients from these characteristic changes to skin ${ }^{(21-}$ ${ }^{23)}$.Therefore; in this study, the dermatological diagnoses were based mainly on clinical grounds; which reflects dermatological practice in developing countries, where clinical accuracy for the diagnosis of common dermatoses appears to be good. In addition, the unusual features / complications which were observed mainly showed an exaggerated pattern that making the diagnosis easier. Moreover, the number and degree of adverse cutaneous effects was correlated with the duration of use (results not shown).

The chief seduction of TC lies in their pharmacological properties, like the antiinflammatory and vasoconstrictive effects, that are responsible for their dramatic effects on suppressing whatever the initial primary dermatosis and this will encourage the patients to continue on this "magical drug" use without the supervision of the medical authorities ${ }^{(24,25)}$, that what were demonstrated in our study about the misuse of TC (Table 3).

Unfortunately, an important finding of this study that the most commonly used preparations were classed as potent and very potent TC including, Betamethasone (51\%), Clobetasol (29\%), alone and/or in combination with other products. In spite of the fact that these drugs should be avoided on sensitive sites such as the face, groin and armpits and can cause serious side-effects, they are sold without medical prescription or control. This result is in concordance with other studies from other countries $^{14-19}$.
TC should not be used on the face except for acute inflammatory conditions, provided that it will be not used for more than one month ${ }^{(26,27)}$.However, in this study, we observed facial cutaneous disorders on presentation (Table 3) that were diagnosed as complications of the misuse of TC for cosmetic practice $(62.4 \%)$ as for skin fairness, melasma, dryness, dermatitis and acne. Fifty one percent of the patients were in the age between 13-30 years age. This was probably be expected as this is the period when young people start to take care of their appearance.

Since Beauty is the element craved by every human, in this study, skin lightening was the main reason for the use of the drugs $(30.6 \%)$. This prevalence is similar to that reported by Del and Yves in Senegalese women $^{(28)}$. Our data was limited to facial use, whereas other studies reported that TC as skin lightening used anywhere on the body. The majority of patients were young women from a low social class and poorly educated. However, Adebajo reported that the misuse of TC products was widespread across all sections of the African population, irrespective of socioeducational level or employment. Not only young women reported to use TC as skin lightener, but young men also regularly used them as well. These results could be comparable to other studies carried out in Dakar, Senegal and Lome, where steroids used as bleaching agent, and both males and females indulged in this practice ${ }^{(29,30)}$. The motives for such practicing among young - aged group were to look beautiful, attractive, and have a fair skin without blemishes as well as to treat pigmentery disorders ${ }^{(12,23,31)}$.

Betamethsone/mometasone, hydroquinone and tretinoin-containing skinlightening formulas as well as Melacare ${ }^{\mathrm{TM}}$ have recently become very popular in our country and these were most 
commonly misused products in our study. "Magic mix" is a combination of skin bleaching preparations of unknown or herbal components of poor quality mixed with potent TC and/or crushed dexamethasone tablet is the other recent popular formula in our city that used by $9 \%$ of women in this study. In spite of the obvious side effects of these products, $63.9 \%$ of users did not feel guilty for using such medication for long periods of time because of their unrealistic eagerness to get a "quick cure" for lightening intention.

An important finding of this study was that the majority of participants bought their some skin bleaching products from pharmacies, which offer a guarantee that the products are not counterfeits or of inferior quality or of dubious composition as have been reported by other investigators $^{14,} 32,33$. However, most of participants were not aware of their side effects, one would have expected the pharmacists to have informed them of the side effects. It is a matter of concern that some participants bought TC products and/or "Magic mix", from beautician and flea markets. The seller in these markets may not be aware about a harm of these products. For this reason, clinicians and pharmacists need to raise awareness of the public health impact of this dangerous practice and the effects of continued use and the difficulty to reverse some of the cutaneous complications, particularly the pigmentary problems, via health education programmes through various media including leaflets, television and radio.

This study demonstrate that $8.4 \%$ of patient use TC for treatment of acne. In fact, TC can facilitate the proliferation of Propionibacterium acnes. So patients who misuse TC have developed steroid-induced acne which has been suppressed with the continued use of corticosteroids ${ }^{(23)}$. Therefore, long term use of potent TC should not be stopped abruptly. Instead, patients should be gradually weaned off by reducing to weaker concentrations before stopping them altogether, in addition to administration of a course of systemic antibiotics( doxycycline $100 \mathrm{mg} /$ daily) to prevent any occurrence of acne ${ }^{(9)}$.

Other important demonstration of this study about TC misuses, that these drugs were used for napkin rash, intertrigo, dermatitis, fungal infection and scabies ${ }^{(4)}$. The flexural areas such as groin, axillae, infra-mammary and other intertrigenous are self-occlusive by skin folds that will also enhance absorption of TC, so need to be treated with medium to low potency preparations $^{(34)}$. However, $23 \%$ of the patients used Nystacort ${ }^{\mathrm{TM}}$ and Quadriderm ${ }^{\mathrm{TM}}$ cream that contain potent steroids.

TC and Clotrimazole are an effective topical agent for treating intertrigo; however, potent steroids should not be used in these areas. In addition, TC may suppress the normal cutaneous immune response to dermatophytes and thus enhance fungal infections and produce 'tinea incognito', an atypical presentation of tinea which loses much of its erythema and scaling because of the antiinflammatory properties of corticosteroids. Fisher D had observed cases of tinea with Lotrisone uses which contains betamethasone, that seemed to have a dominant effect over the antifungal aspect of the clotrimazole and worsened rather than cleared the tinea ${ }^{(9)}$. Furthermore, striae, atrophy, telangiectasia and stellate pseudoscars were observed with the prolonged use of the high-potency $\mathrm{TC}^{(34)}$. Most of the adverse reactions may be reversible to some extent upon discontinuation, with the exception of atrophic striae which are not reversible, however, can be minimized by the use of topical tretinoin $^{(35-37)}$. 
Another interesting finding of this study was hypertrichosis on pubic area was found in 3 cases of children who used Nystacort $^{\mathrm{TM}} \quad$ cream, containing Triamcinolone, for diaper rash more than one month. This might be the result of the use of occlusive diapers which have important ramifications on safety of TC use in children increasing the possibility of significant side effects of locally applied TC ${ }^{(22)}$. In $26 \%$ of cases physicians prescribed Nystacort or Quadriderm for treatment of intertrigo for children and adult. Therefore; This study highlighted the importance of a physician familiarity with one or two agents in each category of potency of TC for safely and effectively treat steroid-responsive skin conditions.

In this study, the main burden of responsibility for the misuse of $\mathrm{TC}$ was put on paramedical personnel $(73.6 \%)$.This is probably an exaggeration since most products are easily available from nonpharmaceutical shops and nursing staff without a medical prescription or seeing a doctor. In fact, non-pharmaceutical sources of TC were $36.7 \%$ of the drugs in this study. Secondary responsibility is carried by the pharmacists, general physicians and even some dermatologists.

All patients and caregivers should be taught about the correct amount of TC to be applied in a particular case. In this regard, the use of fingertip units (FTU) should be taught to the patients and the expected number of FTUs required to adequately treat the target area should be conveyed to them ${ }^{(38)}$. Other possible measures to minimize their adverse effects by using topical keratolytics such as salicylic acid, may be used simultaneously for thickened plaques, obviating the need for high-potency steroids and facilitating substitution with lower-potency ones ${ }^{(8)}$.

In conclusion, inappropriate use of TC is a big problem in our country. Easy availability of very potent products without a prescription makes misuse very common which has a huge impact on dermatological practice. It is a multiphase problem that needs the cooperation of different sectors in the community to overcome it. Education of the general public through special media programs and the introduction of a continuing medical education programs for medical and paramedical personnel as well as controlling the easy intake from pharmacies are probably the most important steps that could be taken to reduce this problem.

\section{References}

1. Stern R. The pattern of topical corticosteroid prescribing in the United States 1989-1991. J Am Acad Dermatol 1996; 35:183-96.

2. Sulzberger M, Witten V. The effect of topically applied compound $\mathrm{F}$ in selected dermatoses. J Invest Dermatol 1952;19:101-2.

3. Kumar A, Noushad P, Shailaja K, et al. A study on drug prescribing pattern and use of corticosteroids in dermatological conditions at tertiary care teaching hospital. Int J Pharm Sci Rev Res 2011;9:132-5.

4. Sanjay K, Paschal D. Rational and ethical use of topical corticosteroids based on safety and efficacy. Indian $\mathrm{J}$ Dermatol 2012;57(4):251-259.

5. Ference J, Last AR. Choosing Topical Corticosteroids. Am Fam Physician 2009;79:135-40.

6. Wikipedia, the free encyclopedia. Steroid atrophy 2013. Retrieved from http://en.wikipedia.org/w/index.php?title $=\mathrm{S}$ teroid atrophy\&oldid $=548820607$

7. Sanjary R. Abuse of topical steroid as cosmetic cream: A social background of steroid dermatitis. IJD 2006;51(2):154-155. 
8. Ulrich R, Thomas R, Robert A, et al. Adverse effects of topical glucocorticosteroids. J Am Acad Dermatol 2006;54(1).

9. Fisher D. Adverse effects of topical corticosteroid use. West J Med 1995; 162:123-126.

10. Vivier A. Tachyphylaxis to topically applied steroids. Arch Dermatol 1976; 112:1245-1248.

11. De Souza M. The concept of skin bleaching in Africa and its devastating health implications. Clin Dermatol 2008; 26(1): 27-29.

12. Science in Africa, Africa's First OnLine Science Magazine.2004.

13. Noruka E, Okoye O. Topical steroid abuse: its use as a depigmenting agent. J Natl Med Assoc 2006; 98: 934-939.

14. Mahe A. Skin diseases associated with the cosmetic use of bleaching products in women from Dakar, Seneegal. British journal of dermatology, 2003, 148(3):493500.

15. Wester R, Maibach $H$. In vivo percutaneous penetration: Dermatotoxicology, 4th edition. Washington, DC, Hemisphere Publishing, 1991;75-96.

16. Lagos B, Maibach H. Frequency of appplication of topical corticosteroids: an overview. British journal of dermatology, 1998, 139(5):763-6.

17. Brodkin R, Janniger C. The artful use of topical steroids. Cutis, 1998, 61(3):1256.

18. $\mathrm{Lu} \mathrm{H}, \mathrm{Xiao} T$, Lu B, et al. Facial corticosteroid addictive dermatitis in Guiyang city, China. Clin Exp Dermatol 2009;35:618-21.

19. Solomon B, Glass A, Rabbin P. Tinea incognito and "over- the- counter" potent topical steroids. Cutis 1996;58:295-6.

20. Al-Dhalimi M, Aljawahiri N. Misuse of topical corticosteroids: A clinical study from an Iraqi hospital. East Mediterr Health J 2006;12:847-52.
21. Mansour A, Akream H, Hameed L. Corticosteroid Nonprescription Use: A Cross-Sectional Hospital-Based Study in Basrah. Princ Pract 2010;19:182-187

22. Abir S, Koushik L, Manas C, et al. Topical corticosteroid abuse on the face: A prospective, multicenter study of dermatology outpatients. IJDVL 2011;77(2):160-166.

23. Rod H and Paul B. Hazards of Using Skin Bleaching Agents. J Comm Dermatol 2009 ; 6: 13-24.

24. Ammar F. Steroid Dermatitis Resembling Rosacea: A Clinical Evaluation of 75 Patients.ISRN Dermatology 2013;491376: 4.

25. Raveenthiran V. Misuse of Corticosteroids in Infants of Rural Tamilnadu. Indian Pediatrics 2008;45:17.

26. Dubertret L. Which steroids for the treatment of skin disorders on the face? Journal of the European Academy of Dermatol Venereol 2002;16(2):121.

27. Prawer S and Katz H. "Guidelines for using super potent topical steroids". Am Family Physician 1990;41(5):1531-1538.

28. Del P and Yves P. The widespread use of skin lightening creams in Senegal: a persistent public problem in West Africa. International Journal of Dermatology 2002; 41(2):69-72.

29. Wone 1, Tal-Dia A, Diallo OF, et al. Prevalence of the use of skin bleaching cosmetics in two areas in Dakar, Senegal (French). Dakar Med. 2000; 45(2):154-157. 30. Pitche $P$, Afoune A, Amage U, et al. Prevalence of skin disorders associated with the use of bleaching cosmetics by Lome women (French). Sante1997; 7(3):1614.

31. Syed H, Ali S, Zohaib F, et al. SkinLightening Practice among Women living in Lahore.2013 website: http://cgr.umt.edu.pk/icobm2013/index.

32. Malangu N. Predictors of topical steroid misuse among patrons of 
pharmacies in Pretoria. S A Fam Pract 2006; 48(1).

33. Boyle J, Kennedy C. Hydroquinone concentrations in skin lightening creams. British Journal of Dermatology 1986; 114(4):501-4.

34. Tadicherla S, Ross $K$, Shenefelt PD, Fenske NA. Topical corticosteroids in dermatology. J Drugs Dermatol 2009; 8:1093-105.

35. Ann H, Brenda P, Pamela W. Topical steroids. Lippincott's nursing Center.Com 2011; 9(4):49 - 50 .
36. Steven E and Katz H. Guidelines for using superpotent topical steroids American Academy of Family Physician 1990.

37. Kligman L, Schwartz E, Mezick J. Topical tretinoin prevents corticosteroidinduced atrophy without lessening the antiinflammatory effect. Curr Probl Dermatol 1993; 21:79-88.

38. Long CC, Mills CM, Finlay AY. A practical guide to topical therapy in children. Br J Dermatol 1998; 138:293-6. 